\title{
Selection of the Solvent and Extraction Conditions for Maximum Recovery of Antioxidant Phenolic Compounds from Coffee Silverskin
}

\author{
Lina F. Ballesteros • José A. Teixeira • Solange I. Mussatto
}

Received: 6 February 2013 /Accepted: 11 April 2013 /Published online: 28 April 2013

(C) Springer Science+Business Media New York 2013

\begin{abstract}
The extraction of antioxidant phenolic compounds from coffee silverskin (CS) was studied. Firstly, the effect of different solvents (methanol, ethanol, acetone, and distilled water) on the production of antioxidant extracts was evaluated. All the extracts showed antioxidant activity (FRAP and DPPH assays), but those obtained with methanol and ethanol had significantly higher $(p<0.05)$ DPPH inhibition than the remaining ones. Due to the lower toxicity, ethanol was selected as extraction solvent, and further experiments were performed in order to define the solvent concentration, solvent/solid ratio, and time to maximize the extraction results. The best condition to produce an extract with high content of phenolic compounds (13 mg gallic acid equivalents/g CS) and antioxidant activity $[\mathrm{DPPH}=18.24 \mu \mathrm{mol}$ Trolox equivalents/g CS and FRAP $=$ $0.83 \mathrm{mmol} \mathrm{Fe}(\mathrm{II}) / \mathrm{g} \mathrm{CS}]$ was achieved when using $60 \%$ ethanol in a ratio of $35 \mathrm{ml} / \mathrm{g} \mathrm{CS}$, during $30 \mathrm{~min}$ at $60-65^{\circ} \mathrm{C}$.
\end{abstract}

Keywords Coffee silverskin · Solvent · Extraction ·

Phenolic compounds $\cdot$ Antioxidant activity

$\begin{array}{ll}\text { Abbreviations } \\ \text { BSA } & \text { Bovine serum albumin } \\ \text { CS } & \text { Coffee silverskin } \\ \text { DPPH } & \text { 2,2-Diphenyl-1-picrylhydrazyl } \\ \text { FRAP } & \text { Ferric reducing antioxidant power } \\ \text { GAE } & \text { Gallic acid equivalents }\end{array}$

L. F. Ballesteros $\cdot$ J. A. Teixeira $\cdot$ S. I. Mussatto $(\triangle)$ Institute for Biotechnology and Bioengineering (IBB), Centre of Biological Engineering, University of Minho, Campus Gualtar, 4710-057 Braga, Portugal

e-mail: solange@deb.uminho.pt

S. I. Mussatto

e-mail: solangemussatto@hotmail.com $\begin{array}{ll}\text { PC } & \text { Phenolic compounds } \\ \text { QE } & \text { Quercetin } \\ \text { TE } & \text { Trolox equivalents }\end{array}$

\section{Introduction}

Phenolic compounds, being considered secondary metabolites produced by different plants, are ingredients of great interest for chemical, pharmaceutical, and food industries because they have multiple biological effects, including antioxidant activity that provide enormous benefits for human health. It has been shown that such compounds reduce the incidence of degenerative diseases, such as cancer and diabetes, and decrease the risk factors of cardiovascular diseases since they have antioxidant, antimutagenic, antiallergenic, anti-inflammatory, and antimicrobial effects (Jiménez et al. 2008; Ao et al. 2011; Martins et al. 2011). Additionally, phenolic compounds improve the organoleptic properties of many food of vegetable origin, and they are used as natural preservatives against food degradation as well as raw material in the development of functional food (Rodríguez-Meizoso et al. 2010).

Nowadays, interest in reusing fruits, vegetables, plant seeds, and agroindustrial wastes to obtain antioxidant phenolic compounds has increased. Coffee silverskin (CS), which is the thin tegument of the outer layer of green coffee beans, is the major by-product of the coffee roasting process. Although this waste has been used as fuel, soil fertilizer, and for composting, it is not completely utilized and, hence, generates much pollution (Mussatto et al. 2011a). Some researchers have explored the use of CS as functional ingredient due to its high content of soluble dietary fiber, low level of fat, reducing carbohydrates, and marked antioxidant capacity (Borrelli et al. 2004). In this sense, CS can 
be considered as an interesting source to obtain antioxidant compounds since it is an inexpensive and greatly available feedstock.

A great variety of techniques can be used for recovering antioxidant phenolic compounds from agroindustrial residues and natural resources, which include solid-liquid extraction, autohydrolysis, microwave-assisted extraction, ultrasound-assisted extraction, and others (Cortazar et al. 2005; Markom et al. 2007; Martins et al. 2010). Among these techniques, solid-liquid extraction has been widely employed to isolate different compounds. This technique can be defined as a process able to separate one constituent from a mixture by dissolving it into solvent in which it is soluble, but in which the other constituents of the mixture are not, or are at least less soluble (Lebovka et al. 2011). However, the efficiency of the extraction process is affected by the type of solvent used and its concentration, the solvent/solid ratio, time of contact, temperature, and particle size of the solid matrix (Chirinos et al. 2007; Mussatto et al. 2011b; Meneses et al. 2013). Therefore, it is necessary to select the conditions that maximize the recovery of the desired compound for each raw material.

Despite the fact that some few recent studies have reported the extraction of phenolic compounds from CS (Machado et al. 2011; Murthy and Naidu 2012; Narita and Inouye 2012), to the best of our knowledge, there is not any study in the literature on the extraction of these components from CS using organic solvents such as ethanol, methanol, and acetone. In this sense, the purpose of the present study was to select the solid-liquid extraction conditions in order to maximize the recovery of antioxidant phenolic compounds from CS. Initially, the effect of different solvents (methanol, ethanol, acetone, and distilled water) on the extraction of antioxidant compounds was evaluated. Subsequently, solid-liquid extractions were performed using the selected solvent at different concentrations, solvent/solid ratios, and extraction times, and the effects of these operational variables on the extraction results were verified. Finally, the conditions able to produce a phenolic rich extract with high antioxidant activity were established. This is the first study on the recovery of antioxidant phenolic compounds from CS using ethanol, methanol, and acetone as extraction solvents. Additionally, the optimization of the conditions to maximize the extraction of antioxidant phenolic compounds from CS has also not been reported yet. This optimization stage increases the importance of the present study when compared to others studies published in the literature, since it allows a more suitable and complete exploitation of the CS residue, saving time, reagents, and manpower, and doing the process more economical and reliable.

\section{Materials and Methods}

Sample Material and Chemicals

CS was supplied by the Portuguese coffee industry NovaDelta-Comércio e Indústria de Cafés S.A. (Campo Maior, Portugal). The material (about $5 \%$ moisture content) was ground to fine powder and stored at room temperature for further extractions. Gallic acid, 2,2-diphenyl-1-picrylhydrazyl (DPPH), 2,4,6-tris(1-pyridyl)-5-triazine (TPTZ), iron(III) chloride, quercetin, aluminum chloride, sodium acetate, potassium acetate, ferrous sulfate, and Folin-Ciocalteau's reagent were purchased from Sigma-Aldrich (Chemie $\mathrm{GmbH}$, Sternheim, Germany). Sodium carbonate and acetic acid were acquired from Panreac Química (Barcelona, Spain). Coomassie protein assay reagent and bovine serum albumin (BSA) standard ampoules $(2 \mathrm{mg} / \mathrm{ml}$ in a solution of $0.9 \%$ saline and $0.05 \%$ sodium azide) were purchased from Thermo Scientific (Rockford, IL, USA). Analytical reagent grade methanol, ethanol, and acetone were obtained from Fisher Scientific (Leicestershire, UK) and ultrapure water from a Milli-Q System (Millipore Inc., USA) was used.

\section{Solid-Liquid Extraction}

In the first part of the study, solid-liquid extractions were performed by mixing $1 \mathrm{~g}$ of CS with $20 \mathrm{ml}$ of organic solvent [methanol, ethanol or acetone at concentrations of $50 \%$ and $90 \%(v / v)]$ or distilled water. The mixtures were done in 100 $\mathrm{ml}$ Erlenmeyer flasks, which were duly covered to avoid solvent loss and were heated during $30 \mathrm{~min}$ in a water-bath with magnetic agitation at $60-65^{\circ} \mathrm{C}$. After this time, the produced extracts were centrifuged $(2,500 \times g, 20 \mathrm{~min})$, filtered through $0.22-\mu \mathrm{m}$ filters and stored at $-20^{\circ} \mathrm{C}$ until further analysis.

For the extraction solvent selected in the previous stage, new experimental assays were carried out at $60-65^{\circ} \mathrm{C}$ using different conditions of solvent concentration $(20-90 \%, v / v)$, solvent/solid ratio (10-40 ml/g CS) and extraction time (30-90 $\mathrm{min}$ ), which were combined according to a $2^{3}$ facecentered central composite design. Subsequently, each extract was centrifuged at the same conditions used in the initial experiments, and the supernatant was filtered and stored until analyses.

The volume of extract recovered after each extraction was quantified and used for calculations. All the experimental conditions and determinations were performed in triplicate.

Analytical Methodology

\section{Phenolic Compounds}

The total content of phenolic compounds in CS extracts was determined using the Folin-Ciocalteu reagent according to 
the colorimetric method described by Singleton and Rossi (1965), adapted to a 96-well microplate. For the reactions, $5 \mu \mathrm{l}$ of each filtered and duly diluted extract were mixed with $60 \mu \mathrm{l}$ of sodium carbonate solution at $7.5 \%(w / v)$ and $15 \mu \mathrm{l}$ of Folin-Ciocalteu reagent. Subsequently, $200 \mu \mathrm{l}$ of distilled water was added, and the solutions were mixed. Thereafter, the samples were heated at $60{ }^{\circ} \mathrm{C}$ for $5 \mathrm{~min}$ and were allowed to cool at room temperature. The absorbance was then measured by means of a spectrophotometric microplate reader (Sunrise Tecan, Grödig, Austria) set at $700 \mathrm{~nm}$. A calibration curve was made from gallic acid standard solutions $(200,400,600,800,1,000,2,000$, and $3,000 \mathrm{mg} / \mathrm{l}$ ), and the blank was prepared with distilled water. The total content of phenolic compounds was expressed as milligram gallic acid equivalent per dry weight material ( $\mathrm{mg}$ GAE/g CS).

\section{Ferric Reducing Antioxidant Power Assay}

The antioxidant activity of CS extracts by the ferric reducing antioxidant power (FRAP) assay was determined according to the method described by Benzie and Strain (1996) with some modifications. A $10-\mu 1$ aliquot of the filtered and duly diluted extract was mixed with $290 \mu$ of FRAP reagent in a 96-well microplate, and incubated at $37^{\circ} \mathrm{C}$ for $15 \mathrm{~min}$. After that, the absorbance was determined at $593 \mathrm{~nm}$ using distilled water as blank. FRAP reagent was freshly prepared by mixing a 10-mM 2,4,6-tris (1-pyridyl)-5-triazine solution in $40 \mathrm{mM} \mathrm{HCl}$ with a $20-\mathrm{mM} \mathrm{FeCl}_{3}$ solution and $0.3 \mathrm{M}$ acetate buffer ( $\mathrm{pH}$ 3.6) in a proportion 1:1:10 $(v / v / v)$. A calibration curve was constructed using an aqueous solution of ferrous sulfate $\left(\mathrm{FeSO}_{4} \cdot 7 \mathrm{H}_{2} \mathrm{O}\right.$ at $200,400,600,800$, and $\left.1,000 \mu \mathrm{M}\right)$. The FRAP values were expressed as millimoles of ferrous equivalent per dry weight material (mmol $\mathrm{Fe}(\mathrm{II}) / \mathrm{g} \mathrm{CS}$ ).

\section{Free Radical Scavenging Activity (DPPH assay)}

The DPPH radical scavenging activity of CS extracts was determined according to method described by Hidalgo et al. (2010) with some modifications. For the reactions, $10 \mu \mathrm{l}$ of each duly diluted extract was added to $290 \mu$ of DPPH solution $\left(6 \times 10^{-5} \mathrm{M}\right.$ in methanol and diluted to an absorbance of 0.700 at $517 \mathrm{~nm}$ ) in a 96-well microplate. The resulting solutions were vortexed and allowed to stand for $30 \mathrm{~min}$ in darkness at room temperature. Then, the absorbance was measured at $517 \mathrm{~nm}$ in a spectrophotometric microplate reader (Sunrise Tecan, Grödig, Austria) using methanol as blank. The control solution consisted in using methanol instead of the sample. The radical scavenging activity was calculated by using the Eq (1), where $A_{\mathrm{c}}$ and $A_{\mathrm{s}}$ are the absorbance of the control solution and the absorbance of the sample solution, respectively. The DPPH values of the each sample were expressed as micromoles of trolox equivalents (TE) per dry weight material $(\mu \mathrm{mol}$ TE/g CS).

$\%$ inhibition of DPPH $=\left(1-\mathrm{A}_{\mathrm{s}} / \mathrm{A}_{\mathrm{c}}\right) \times 100$

\section{Flavonoids}

The total content of flavonoids was estimated by colorimetric assay as described by Chang et al. (2002) with some modifications. A volume of $30 \mu \mathrm{l}$ of the filtered and duly diluted extract was sequentially added to $90 \mu \mathrm{l}$ methanol, $6 \mu \mathrm{l}$ aluminum chloride at $10 \%(w / v), 6 \mu \mathrm{l}$ potassium acetate $(1 \mathrm{~mol} / \mathrm{l})$, and $170 \mu \mathrm{l}$ distilled water, in a 96-well microplate. The mixtures were maintained during $30 \mathrm{~min}$ in the dark at room temperature, and the absorbance was then measured at $415 \mathrm{~nm}$ against a blank of distilled water using a spectrophotometric microplate reader (Sunrise Tecan, Grödig, Austria). A calibration curve was prepared with a standard solution of quercetin $(25,50,100,150$, and $200 \mathrm{mg} / \mathrm{l})$. The content of total flavonoids was expressed as milligram quercetin equivalent per dry weight material (mg QE/g CS).

\section{Protein}

Protein was estimated by the Bradford assay (Bradford 1976) adapted to a 96-well microplate. Briefly, $10 \mu \mathrm{l}$ of

Table 1 Antioxidant potential (DPPH and FRAP assays) of the extracts produced by solid-liquid extraction of coffee silverskin using different solvents

\begin{tabular}{|c|c|c|c|c|c|}
\hline \multicolumn{3}{|c|}{ Organic solvents at $50 \%(v / v)$} & \multicolumn{3}{|c|}{ Organic solvents at $90 \%(v / v)$} \\
\hline & DPPH ( $\mu \mathrm{mol} \mathrm{TE} / \mathrm{g}$ CS) & FRAP (mmol Fe(II)/g CS) & & DPPH ( $\mu \mathrm{mol}$ TE/g CS) & FRAP (mmol Fe(II)/g CS) \\
\hline Distilled water & $9.21 \pm 0.12 \mathrm{a}$ & $0.061 \pm 0.004 \mathrm{a}$ & Distilled water & $9.21 \pm 0.12 \mathrm{a}$ & $0.061 \pm 0.004 \mathrm{~b}$ \\
\hline Acetone & $9.83 \pm 0.19 \mathrm{~b}$ & $0.083 \pm 0.009 \mathrm{~b}$ & Acetone & $10.24 \pm 0.38 \mathrm{~b}$ & $0.032 \pm 0.006 \mathrm{a}$ \\
\hline Ethanol & $10.01 \pm 0.03 \mathrm{~b}$ & $0.089 \pm 0.003 \mathrm{~b}$ & Ethanol & $10.89 \pm 0.01 \mathrm{c}$ & $0.070 \pm 0.005 \mathrm{~b}$ \\
\hline Methanol & $9.92 \pm 0.15 \mathrm{~b}$ & $0.077 \pm 0.007 \mathrm{~b}$ & Methanol & $10.95 \pm 0.02 \mathrm{c}$ & $0.069 \pm 0006 \mathrm{~b}$ \\
\hline
\end{tabular}

Different letters within a column mean values statistically different at $95 \%$ confidence level 
Table 2 Experimental conditions and results obtained during the extraction of antioxidant phenolic compounds from coffee silverskin (CS)
Assays according to a $2^{3}$ facecentered central composite design

PC phenolic compounds, FRAP antioxidant activity by the ferric reducing antioxidant power assay, $D P P H$ antioxidant activity by the 2,2-diphenyl-1-picrylhydrazyl assay

\begin{tabular}{|c|c|c|c|c|c|c|}
\hline \multirow[t]{2}{*}{ Assay } & \multicolumn{3}{|c|}{ Process variables [real and (coded) values] } & \multicolumn{3}{|l|}{ Responses } \\
\hline & $\begin{array}{l}\text { Ethanol } \\
\text { concentration (\%) }\end{array}$ & $\begin{array}{l}\text { Solvent } / \text { solid } \\
\text { ratio }(\mathrm{ml} / \mathrm{g})\end{array}$ & $\begin{array}{l}\text { Time } \\
(\mathrm{min})\end{array}$ & $\begin{array}{l}\text { PC } \\
(\mathrm{mg} \mathrm{GAE} / \mathrm{g} \mathrm{CS})\end{array}$ & $\begin{array}{l}\text { FRAP } \\
(\mathrm{mmol} \mathrm{Fe}(\mathrm{II}) / \mathrm{g} \mathrm{CS})\end{array}$ & $\begin{array}{l}\text { DPPH } \\
(\mu \mathrm{mol} \mathrm{TE} / \mathrm{g} \mathrm{CS})\end{array}$ \\
\hline 1 & $90(+1)$ & $40(+1)$ & $90(+1)$ & $12.15 \pm 1.45$ & $0.076 \pm 0.002$ & $21.74 \pm 0.46$ \\
\hline 2 & $20(-1)$ & $40(+1)$ & $90(+1)$ & $13.53 \pm 0.58$ & $0.079 \pm 0.003$ & $19.42 \pm 1.32$ \\
\hline 3 & $90(+1)$ & $40(+1)$ & $30(-1)$ & $12.19 \pm 1.78$ & $0.077 \pm 0.007$ & $21.52 \pm 0.83$ \\
\hline 4 & $20(-1)$ & $40(+1)$ & $30(-1)$ & $12.29 \pm 0.94$ & $0.080 \pm 0.003$ & $19.71 \pm 0.69$ \\
\hline 5 & $90(+1)$ & $10(-1)$ & $90(+1)$ & $5.54 \pm 1.72$ & $0.038 \pm 0.006$ & $5.37 \pm 0.06$ \\
\hline 6 & $20(-1)$ & $10(-1)$ & $90(+1)$ & $5.63 \pm 1.32$ & $0.031 \pm 0.006$ & $4.27 \pm 0.25$ \\
\hline 7 & $90(+1)$ & $10(-1)$ & $30(-1)$ & $6.82 \pm 0.59$ & $0.035 \pm 0.001$ & $5.29 \pm 0.11$ \\
\hline 8 & $20(-1)$ & $10(-1)$ & $30(-1)$ & $5.26 \pm 0.48$ & $0.033 \pm 0.008$ & $4.16 \pm 0.46$ \\
\hline 9 & $90(+1)$ & $25(0)$ & $60(0)$ & $7.00 \pm 0.52$ & $0.064 \pm 0.004$ & $13.16 \pm 0.92$ \\
\hline 10 & $20(-1)$ & $25(0)$ & $60(0)$ & $12.80 \pm 1.57$ & $0.073 \pm 0.008$ & $12.50 \pm 0.33$ \\
\hline 11 & $55(0)$ & $25(0)$ & $90(+1)$ & $12.78 \pm 1.64$ & $0.075 \pm 0.007$ & $12.81 \pm 0.30$ \\
\hline 12 & $55(0)$ & $25(0)$ & $30(-1)$ & $12.94 \pm 0.49$ & $0.077 \pm 0.002$ & $12.66 \pm 0.31$ \\
\hline 13 & $55(0)$ & $40(+1)$ & $60(0)$ & $11.88 \pm 1.31$ & $0.088 \pm 0.002$ & $20.93 \pm 0.42$ \\
\hline 14 & $55(0)$ & $10(-1)$ & $60(0)$ & $5.76 \pm 0.48$ & $0.032 \pm 0.011$ & $4.68 \pm 0.26$ \\
\hline 15 & $55(0)$ & $25(0)$ & $60(0)$ & $12.52 \pm 1.24$ & $0.076 \pm 0.002$ & $12.91 \pm 0.13$ \\
\hline 16 & $55(0)$ & $25(0)$ & $60(0)$ & $11.60 \pm 1.29$ & $0.074 \pm 0.002$ & $12.94 \pm 0.09$ \\
\hline 17 & $55(0)$ & $25(0)$ & $60(0)$ & $11.33 \pm 1.65$ & $0.072 \pm 0.004$ & $12.91 \pm 0.12$ \\
\hline 18 & $55(0)$ & $25(0)$ & $60(0)$ & $11.77 \pm 1.35$ & $0.073 \pm 0.004$ & $12.84 \pm 0.16$ \\
\hline
\end{tabular}

the filtered and duly diluted extract was mixed with $300 \mu \mathrm{l}$ of Coomassie Blue reagent in a 96-well microplate. Thereafter, the mixtures were shaken for $30 \mathrm{~s}$ and reserved during $10 \mathrm{~min}$ at room temperature. Later, the absorbance was determined in a spectrophotometer microplate reader (Sunrise Tecan, Grödig, Austria) set at 595 nm, using distilled water as blank. A standard calibration curve was prepared from BSA solution (at 25, 125, 250, 500, 750,
Fig. 1 Correlation analysis chart for the responses total phenolic compounds and antioxidant activity (FRAP assay) of the coffee silverskin extracts obtained by solid-liquid extraction using ethanol as solvent

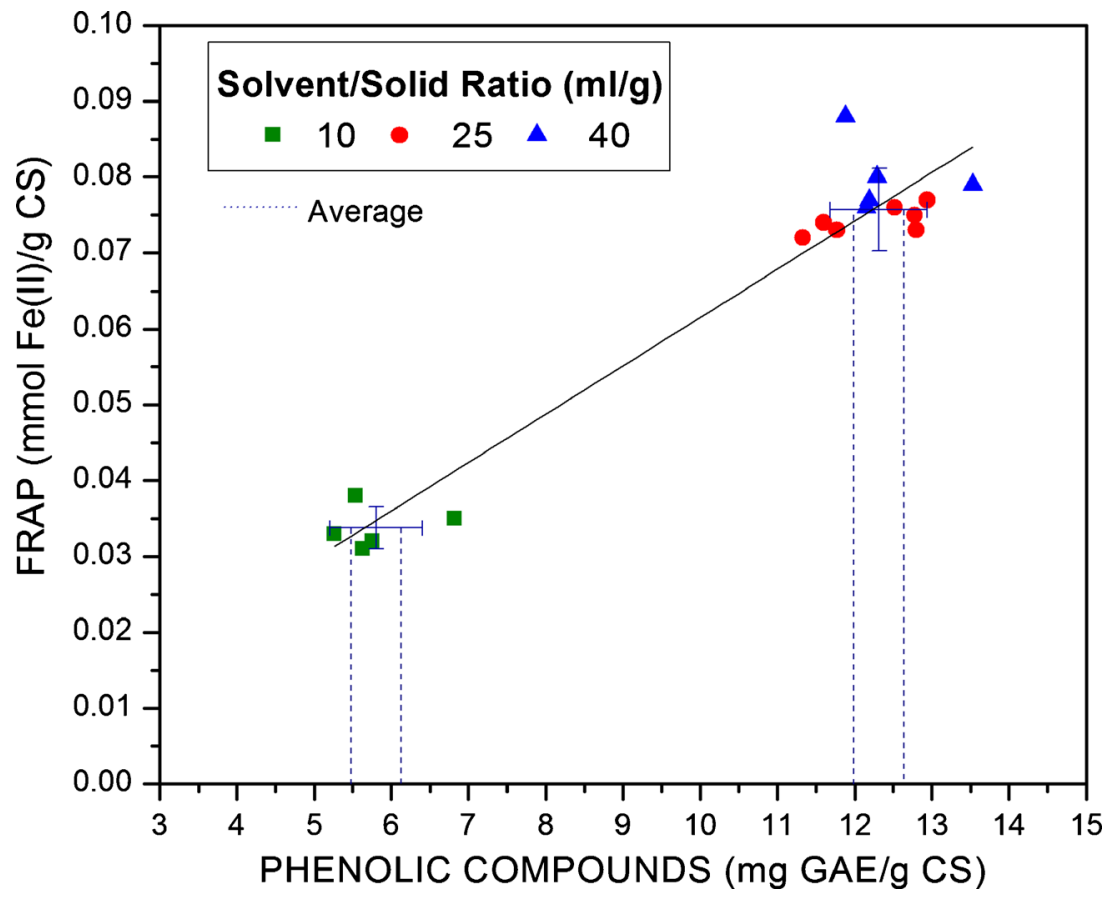


and $1,000 \mathrm{mg} / \mathrm{l})$. The protein content was expressed as milligram BSA equivalent per dry weight material (mg $\mathrm{BSA} / \mathrm{g} \mathrm{CS})$.

\section{Minerals}

Total minerals content was determined by weight difference before and after the sample incineration in a muffle furnace at $550{ }^{\circ} \mathrm{C}$ for $4 \mathrm{~h}$.

\section{Statistical Analyses}

In the first part of the study, statistical analysis of the results was carried out in order to identify the effect of each solvent on the extraction of antioxidant compounds from CS. Difference among the samples was verified by the Tukey's range test considering a significance level of $p<0.05$. In the

a

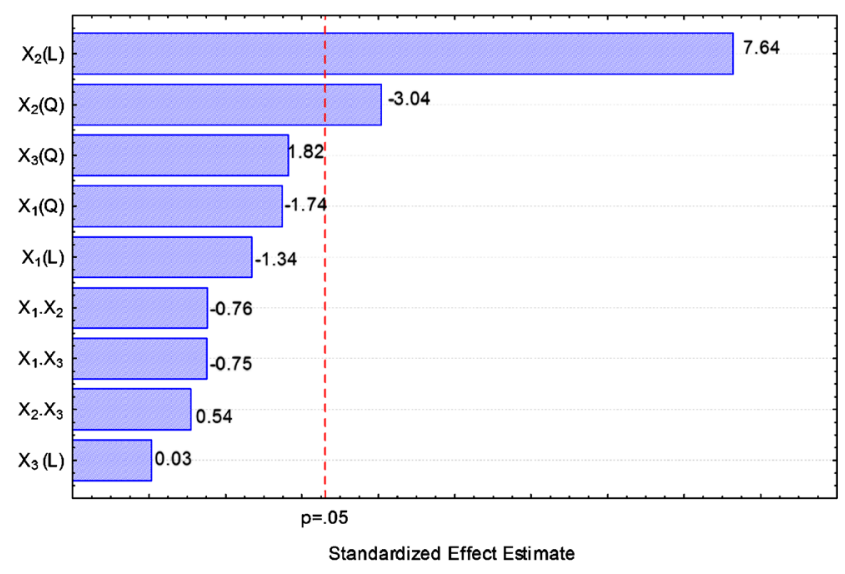

C

FRAP

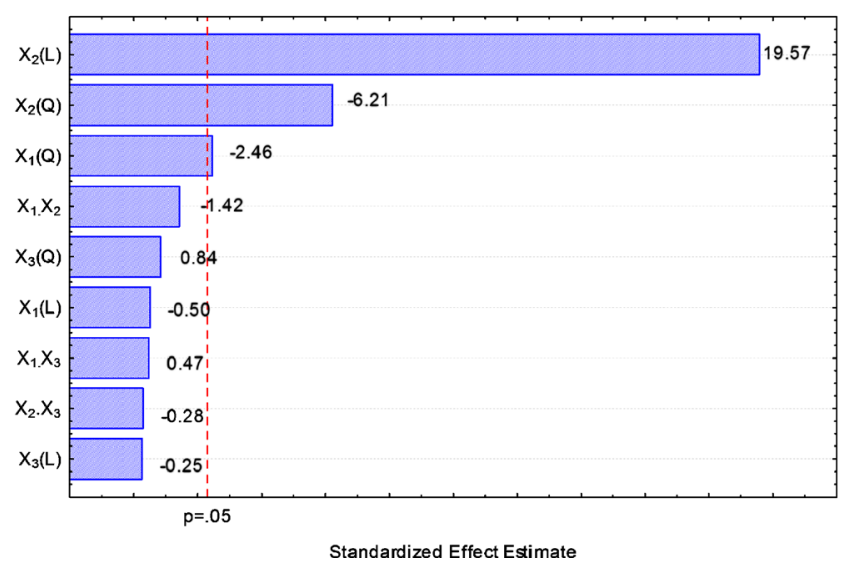

Fig. 2 Pareto chart for the effects of ethanol concentration $\left(X_{1}\right)$, solvent/ solid ratio $\left(X_{2}\right)$, extraction time $\left(X_{3}\right)$, and their interaction $\left(\mathrm{X}_{1} \cdot \mathrm{X}_{2}, X_{1} \cdot X_{3}\right.$, $X_{2}, X_{3}$ ) during the solid-liquid extraction of coffee silverskin, on the total subsequent part of the study, the influence of the variables ethanol concentration, solvent/solid ratio, and time on the extraction of antioxidant phenolic compounds was investigated through a $2^{3}$ face-centered central composite design. Statistical significance of the variables was determined at $5 \%$ probability level $(p<0.05)$. The data obtained from the design were fitted to second-order polynomial equations, and the models were simplified by elimination of statistically insignificant terms. Statistical significance of the regression coefficients was determined by Student's $t$ test, and the proportion of variance explained by the models was given by the multiple coefficient of determination, $R^{2}$. Statistical analysis of the data as well as the determination of the conditions able to maximize the extraction results were performed using the software Statistica (version 8.0), and Design expert (version 8.0).

b

DPPH

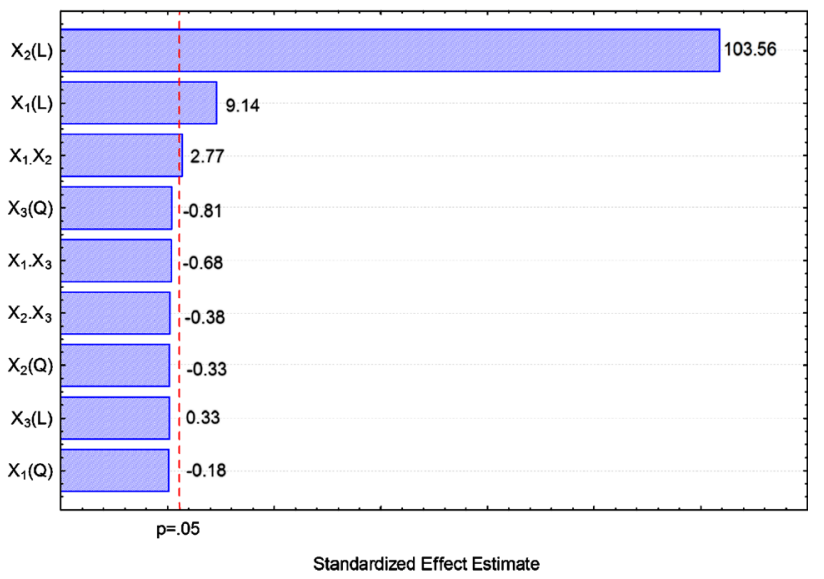

content of phenolic compounds (a), and antioxidant activity [DPPH (b) and FRAP (c) assays] of the produced extracts. $L$ and $Q$ correspond to the effects at linear and quadratic levels, respectively 


\section{Results and Discussion}

\section{Selection of the Extraction Solvent}

In the first part of the study, the effect of different solvents on the extraction of antioxidant compounds from CS was evaluated. Methanol, ethanol, acetone, and water were the solvents evaluated in this stage of this study, since they are the most common solvents used for extraction of phenolic compounds from different raw materials. In order to support the conclusions, assays were performed using the organic solvents in two different concentrations, 50 and $90 \%(v / v)$. As can be seen in Table 1, extracts with antioxidant potential were obtained in all the evaluated conditions, even when using distilled water as solvent. However, for both DPPH and FRAP methods, the organic extracts had significantly higher antioxidant potential than the extracts obtained with distilled water. These results suggest that the extractability of the antioxidant compounds from CS is influenced by the polarity and viscosity of the solvent used (Wijekoon et al. 2011) and could be related to the fact that phenolic compounds are often more soluble in organic solvents less polar than water (Liu et al. 2000; Kim and Lee 2002).

Table 1 shows also that organic solvents at $50 \%(v / v)$ produced extracts with similar antioxidant potential, while at $90 \%(v / v)$, acetone produced extracts with lower DPPH and FRAP values than methanol and ethanol extracts.

For the FRAP assay results, the use of methanol as extraction solvent at 90 or $50 \%(v / v)$ generated extracts with similar antioxidant potential. However, acetone had a significantly higher yield when used at $50 \%(\mathrm{v} / \mathrm{v})$, but the value obtained with $50 \%$ acetone was not different of those obtained with ethanol and methanol at the same concentration level. On the other hand, according to the DPPH results,
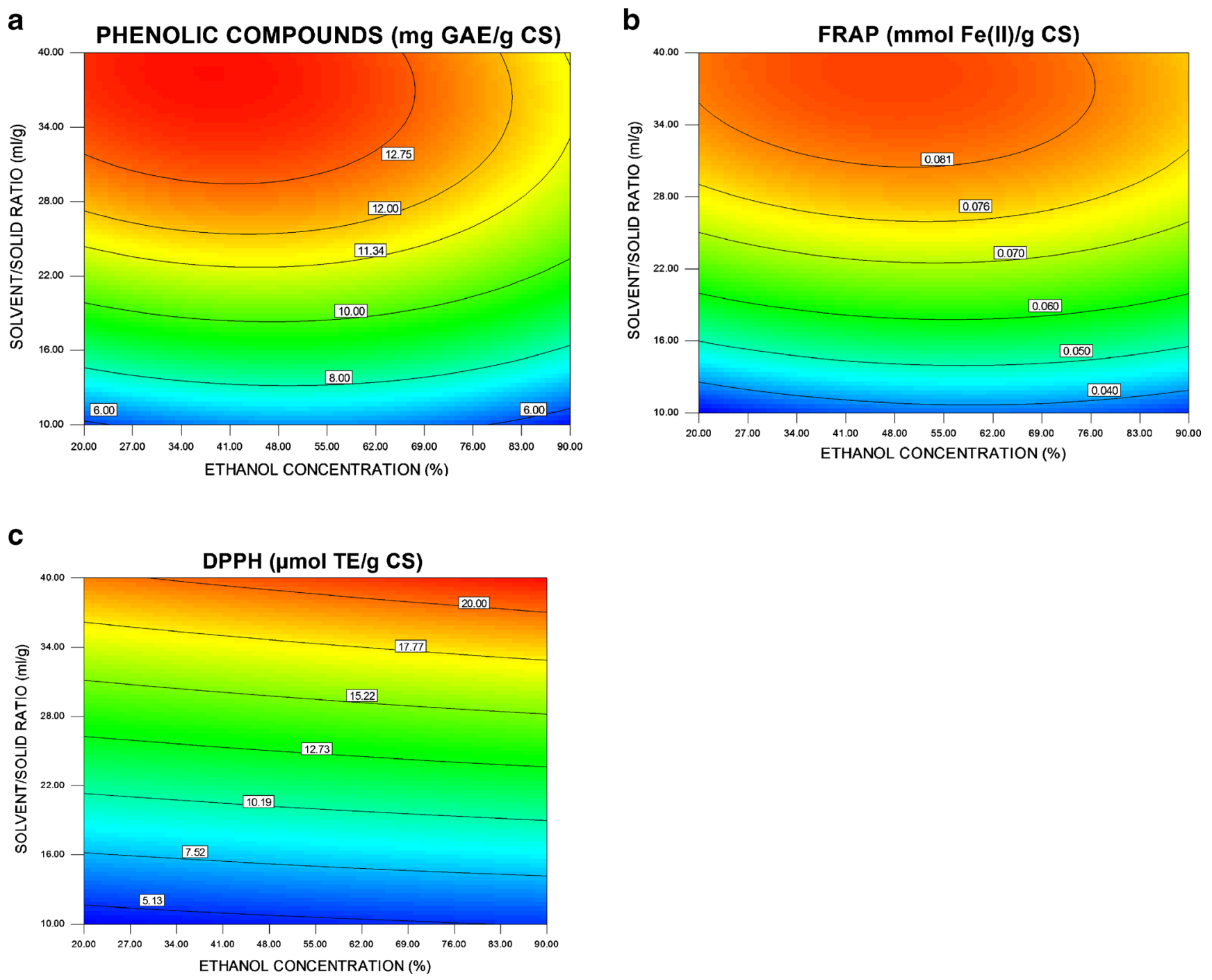

Fig. 3 Contour line plots representing the total content of phenolic compounds (a) and antioxidant activity [FRAP (b) and DPPH (c) assays] of coffee silverskin extracts obtained by solid-liquid extraction with ethanol under different conditions of solvent/solid ratio and ethanol concentration 
extracts obtained by extraction with acetone at $50 \%$ and $90 \%(v / v)$ had similar antioxidant potential, which was significantly lower than the values observed for the extracts produced with ethanol or methanol at $90 \%(v / v)$ (Table 1$)$. The difference observed between the results of FRAP and DPPH assays, (mainly when using acetone as extraction solvent) could be explained by the fact that both methods differ from each other in terms of reaction mechanisms, oxidant and target/probe species, and reaction conditions (Karadag et al. 2009).

Based on the DPPH results, methanol and ethanol at $90 \%(v / v)$ were considered the most suitable solvents for extraction of antioxidant compounds from CS, since the values obtained using these two solvents were higher and statistically different $(p<0.05)$ of all the other values obtained by the DPPH assay. These results are in agreement with other studies, which report that organic solvents, particularly methanol and ethanol, are more efficient than other solvents to extract antioxidant phenolic compounds from different natural sources (Lafka et al. 2007; Spigno et al. 2007; Martins et al. 2010; Trabelsi et al. 2010; Mussatto et al. 2011b; Wijekoon et al. 2011). Since ethanol has a lower toxicity than methanol, it was selected as the best solvent to extract antioxidant compounds from CS.

\section{Optimization of the Extraction Conditions}

After selection of the extraction solvent, assays were performed in order to maximize the recovery of antioxidant phenolic compounds from CS. As it is well known, the solvent concentration, solvent/solid ratio, extraction time, and temperature are key factors in extraction processes, as they affect both the kinetic of phenolic compounds release from the solid matrix and the antioxidant activity of the extracts. Therefore, it is very important to define the conditions of these variables in order to maximize the extraction results. The conditions used in each experimental assay of the present study and the respective results of phenolic compounds concentration, FRAP and DPPH values, are presented in Table 2. Since the temperature increase have been reported to improve the efficiency of extraction due to enhanced diffusion rate and solubility of the compounds in solvents (Dorta et al. 2012), the extraction reactions were not performed at room temperature, but at $60-65^{\circ} \mathrm{C}$, considering the boiling point of the ethanol $\left(78^{\circ} \mathrm{C}\right)$.

According to the results, the operational variables exerted great influence on the extraction of antioxidant phenolic compounds from CS (Table 2). The content of extracted phenolic compounds, for example, varied between 5.26 0.48 (assay 8) and $13.53 \pm 0.58 \mathrm{mg} \mathrm{GAE} / \mathrm{g} \mathrm{CS}$ (assay 2), while the antioxidant activity values increased from $0.031 \pm$ 0.006 (assay 6) to $0.088 \pm 0.002 \mathrm{mmol} \mathrm{Fe}(\mathrm{II}) / \mathrm{g} \mathrm{CS}$ (assay 13 ) by the FRAP assay, and from $4.16 \pm 0.46$ (assay 8 ) to $21.74 \pm 0.46 \mu \mathrm{mol}$ TE/g CS (assay 1) by the DPPH assay. It is interesting to note that the highest content of phenolic compounds obtained in these assays $(13.53 \pm 0.58 \mathrm{mg}$ GAE/g CS) was significantly higher than that obtained by Narita and Inouye (2012) (7 mg GAE/g CS) by supercritical fluid extraction of CS with water at $80{ }^{\circ} \mathrm{C}$. These results confirm the importance of establishing the process conditions in order to maximize the extraction of phenolic compounds from CS.

The content of phenolic compounds in CS was similar to those reported in other natural sources such as ripe raspberry
Fig. 4 Optimum region by overlay plots of the three responses evaluated [phenolic compounds $(P C)$ and antioxidant activity by FRAP and DPPH assays] as a function of the ethanol concentration and solvent/solid ratio used during the extraction process. The variables are presented in their original levels

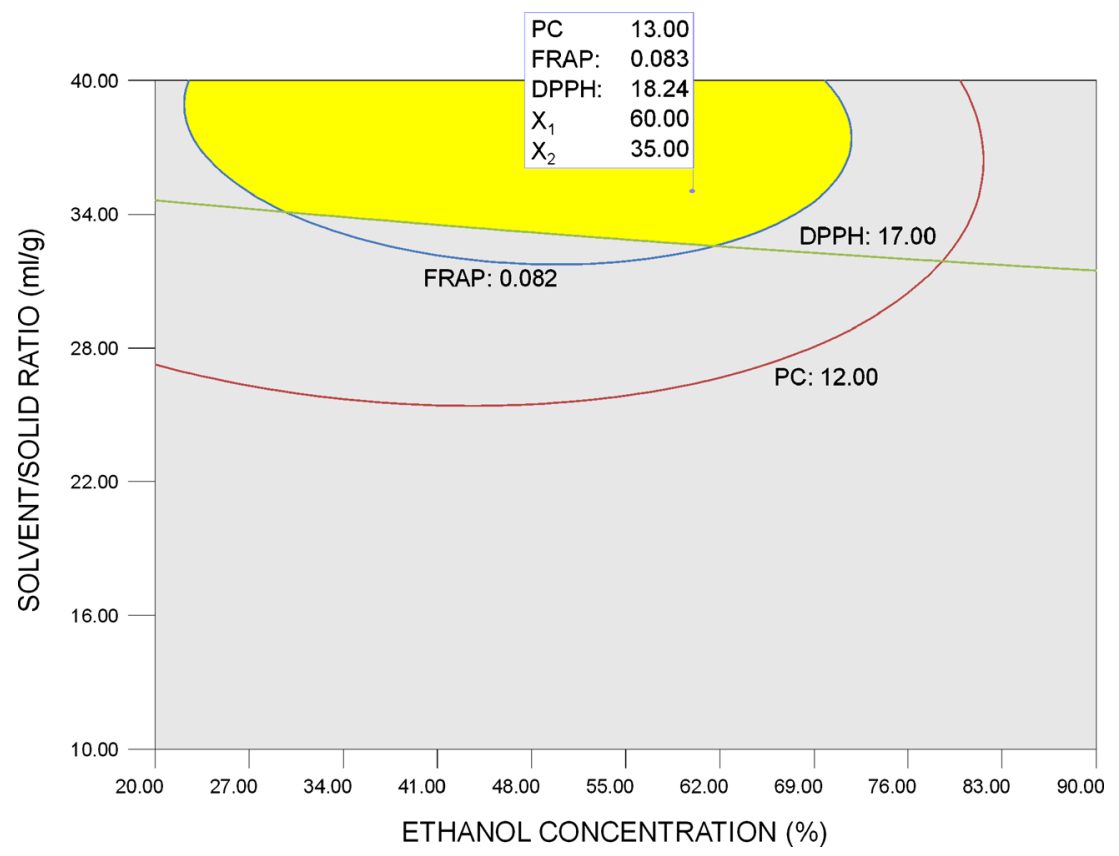


Table 3 Results obtained in the assays for validation of the conditions optimized for extraction of antioxidant phenolic compounds from coffee silverskin (CS)

$P C$ phenolics compounds, FRAP antioxidant activity by the ferric reducing antioxidant power assay, $D P P H$ antioxidant activity by the 2,2-diphenyl-1picrylhydrazyl assay

\begin{tabular}{|c|c|c|c|c|c|c|}
\hline \multirow[t]{2}{*}{$\begin{array}{l}\text { Experimental } \\
\text { assays }\end{array}$} & \multicolumn{3}{|c|}{$\begin{array}{l}\text { Process variables - optimum } \\
\text { point values }\end{array}$} & \multicolumn{3}{|l|}{ Responses } \\
\hline & Ethanol $(\%)$ & $\begin{array}{l}\text { Solvent/solid } \\
\text { ratio }(\mathrm{ml} / \mathrm{g})\end{array}$ & $\begin{array}{l}\text { Time } \\
(\mathrm{min})\end{array}$ & $\begin{array}{l}\text { PC } \\
(\mathrm{mg} \mathrm{GAE} / \mathrm{g} \mathrm{CS})\end{array}$ & $\begin{array}{l}\text { FRAP } \\
(\mathrm{mmol} \mathrm{Fe}(\mathrm{II}) / \mathrm{g} \mathrm{CS})\end{array}$ & $\begin{array}{l}\mathrm{DPPH} \\
(\mu \mathrm{mol} \mathrm{TE} / \mathrm{g} \mathrm{CS})\end{array}$ \\
\hline 1 & 60 & 35 & 30 & $12.86 \pm 1.15$ & $0.100 \pm 0.004$ & $18.00 \pm 0.09$ \\
\hline 2 & 60 & 35 & 30 & $12.77 \pm 1.03$ & $0.097 \pm 0.004$ & $17.96 \pm 0.05$ \\
\hline 3 & 60 & 35 & 30 & $12.80 \pm 1.16$ & $0.097 \pm 0.003$ & $17.89 \pm 0.19$ \\
\hline \multicolumn{4}{|l|}{ Average } & $12.81 \pm 0.07$ & $0.098 \pm 0.002$ & $17.95 \pm 0.06$ \\
\hline \multicolumn{4}{|c|}{ Results predicted by the statistical analysis } & 13.00 & 0.082 & 18.24 \\
\hline
\end{tabular}

(12.0-15.3 mg GAE/g dry matter), blackberry (12.1$14.8 \mathrm{mg} \mathrm{GAE} / \mathrm{g}$ dry matter; Wang and Lin 2000) and Mangifera pajang peel (14.2 mg GAE/g dry matter) (Prasad et al. 2011). Additionally, the antioxidant activity of CS extracts can also be well compared to the values reported in other natural sources as stink bean (Gan and Latiff 2011), Etlingera elatior (Wijekoon et al. 2011), and some fruits including apple, peach, and kiwi (Stratil et al. 2007). These results demonstrate that CS is a phenolic-rich agroindustrial waste with important antioxidant properties.

It is worth emphasizing that antioxidant activity might not always be correlated with phenolic compounds. Therefore, some studies have examined the existence of linear correlation between phenolic compounds and antioxidant activity of the produced extracts (Alothman et al. 2009; Martins et al. 2010). In the present study, a correlation analysis chart was plotted and revealed that the antioxidant activity (FRAP assay) was directly proportional to the content of phenolic compounds present in the CS extracts, the data being correlated with a coefficient $R^{2}=0.9385$ (Fig. 1).

In order to verify the effect of the operational variables on the responses, Pareto charts were plotted (Fig. 2). In this figure, bars extending beyond the vertical line correspond to the effects statistically significant at $95 \%$ confidence level. The solvent/solid ratio $\left(X_{2}\right)$ was the only variable with influence in all the evaluated responses. The ethanol concentration $\left(X_{1}\right)$ did not present significant influence $(p<0.05)$ on the extraction of total phenolic compounds, but affected the antioxidant potential of the produced ex- tracts (Fig. 2b, c). On the other hand, the extraction time $\left(X_{3}\right)$ did not influence any of the responses, which means that 30 min may be considered an enough time to be used in the extraction process. The use of the shortest extraction time is also an important advantage from an economical viewpoint. Similar to the present study, the ethanol concentration and solvent/liquid ratio were also important variables during the extraction of antioxidant phenolic compounds from several other natural sources including M. pajang peel (Prasad et al. 2011), grape seeds (Spigno et al. 2007), and fruits of Euterpe oleracea (Pompeu et al. 2009).

Other important information presented in Fig. 2 is that not only the linear term but also the quadratic term of the variables $X_{1}$ and $X_{2}$ had significant influence on the responses. This result reveals that the value of the responses was not linearly increased by increasing the value of the operational variables, but there was a maximum point after which the values of the responses decreased. Additionally, due to the significance of the quadratic terms, second-order polynomial equations can be defined as being the most suitable to describe the responses variations as a function of the variables variations in the range of values studied. Quadratic models describing the responses variations as a function of the significant process variables (ethanol concentration, $X_{1}$; solvent/liquid ratio, $X_{2}$-coded values) were then established [Eqs. (2), (3), and (4)] and presented high coefficient of determination $\left(R^{2} \geq 0.86\right)$, which means a close agreement between the experimental results and

Table 4 Concentration of phenolic compounds (PC) extracted from coffee silverskin (CS) by different methods

\begin{tabular}{llll}
\hline Extraction method & Process conditions & PC (mg GAE/g CS) & Reference \\
\hline Solid-liquid extraction & Ethanol $60 \%$, solvent/solid ratio $=35 \mathrm{ml} / \mathrm{g}, 60-65{ }^{\circ} \mathrm{C}, 30 \mathrm{~min}$ & 12.81 & Present study \\
Solid-liquid extraction & Water, solvent/solid ratio $=50 \mathrm{ml} / \mathrm{g}, 80{ }^{\circ} \mathrm{C}, 60 \mathrm{~min}$ & 7.00 & Narita and Inouye (2012) \\
Solid-liquid extraction & Isopropanol $60 \%$, solvent/solid ratio $=10 \mathrm{ml} / \mathrm{g}, 27{ }^{\circ} \mathrm{C}$ & 13.20 & Murthy and Naidu (2012) \\
Solid-state fermentation & Cultivation of Penicillium purpurogenum, $30{ }^{\circ} \mathrm{C}, 6$ days & 3.47 & Machado et al. (2011) \\
\hline
\end{tabular}


those predicted by the equations. These models are useful for a rapid prediction of the extraction results to be achieved when using solvent/solid ratios and ethanol concentrations in the range of values here studied.

Phenolic compounds $(\mathrm{PC}$, in mg GAE $/ \mathrm{g} \mathrm{CS})=11.82-0.58 \mathrm{X}_{1}-0.91 \mathrm{X}_{1}^{2}+3.3 \mathrm{X}_{2}-1.99 \mathrm{X}_{2}^{2}-0.37 \mathrm{X}_{1} \mathrm{X}_{2} \quad ; \quad \mathrm{R}^{2}=0.86$

Antioxidant activity(FRAP, in mmol Fe(II) $/ \mathrm{g} \mathrm{CS})=0.074-0.001 \mathrm{X}_{1}-0.005 \mathrm{X}_{1}^{2}+0.023 \mathrm{X}_{2}-0.013 \mathrm{X}_{2}^{2}-0.002 \mathrm{X}_{1} \mathrm{X}_{2} \quad ; \quad \mathrm{R}^{2}=0.98$

Antioxidant activity $(\mathrm{DPPH}$, in $\mu \mathrm{mol}$ Trolox $/ \mathrm{g} \mathrm{CS})=12.86+0.70 \mathrm{X}_{1}-0.07 \mathrm{X}_{1}^{2}+7.95 \mathrm{X}_{2}-0.09 \mathrm{X}_{2}^{2}-0.24 \mathrm{X}_{1} \mathrm{X}_{2} \quad ; \quad \mathrm{R}^{2}=0.99$

Based on the previously established model equations, contour lines graphs were plotted (Fig. 3). These figures clearly show that the region where the values of the responses are maximized is not the same for the three responses. For example, the content of phenolic compounds (Fig. 3a) was increased when the solvent/solid ratio was increased; probably due to the fact that more solvent could react with the CS particles while more phenolic compounds could permeate to the solvent (Prasad et al. 2009). When compared to the solvent/solid ratio, the ethanol concentration had significantly lower effect on the extraction of phenolic compounds; but an ethanol concentration between 20 and $60 \%$ resulted better for the phenolic compounds recovery. This range of concentration values is in agreement with previous studies, which reported that organic solvents mixed with water result to be more effective for extracting phenolic compounds than the organic solvents in the pure form (Mussatto et al. 2011b; Prasad et al. 2011).

The results of the FRAP assay plotted in Fig. $3 b$ had a similar behavior when compared to the results of phenolic compounds presented in Fig. 3a. On the other hand, the results of antioxidant activity by the DPPH assay (Fig. 3c) were maximized in a different region, which consist in the use of an ethanol concentration higher than for the other two responses. This difference can be explained by the fact that the methods commonly used to determine antioxidant activity differ from each other in terms of reaction mechanisms, oxidant and target/probe species, and reaction conditions, as mentioned before (Karadag et al. 2009). However, it would be very useful to find an optimum extraction condition able to simultaneously maximize all the responses (phenolic compounds and antioxidant activity by FRAP and DPPH methods). Considering this aspect, a graphical optimization based on overlaying the curves of these three responses was conducted. In order to find the optimal extraction conditions, the following criteria was adopted: phenolic compounds $\geq 12.00 \mathrm{mg}$ GAE/g CS, FRAP $\geq 0.082 \mathrm{mmol}$ $\mathrm{Fe}(\mathrm{II}) / \mathrm{g} \mathrm{CS}$, and $\mathrm{DPPH} \geq 17.00 \mu \mathrm{mol} \mathrm{TE} / \mathrm{g}$ CS. The overlaying plot attained (Fig. 4) showed an area where all the imposed criteria were satisfied. A point was chosen in this area as optimum point and corresponded to the use of an ethanol concentration of $60 \%(v / v)$ and a solvent/solid ratio of $35 \mathrm{ml} / \mathrm{g}$. Under these conditions, the model predicts a phenolic compounds extraction of $13.00 \mathrm{mg} \mathrm{GAE} / \mathrm{g} \mathrm{CS}$, FRAP of $0.083 \mathrm{mmol} \mathrm{Fe}(\mathrm{II}) / \mathrm{g} \mathrm{CS}$, and DPPH of $18.24 \mu \mathrm{mol} \mathrm{TE} / \mathrm{g}$ CS in the confidence level of $95 \%$.

Assays to validate the optimum extraction conditions were carried out, and the results obtained for phenolic compounds content and antioxidant activity of the produced extract revealed a close agreement with the results predicted by the statistical analysis (Table 3). Finally, the extract obtained under the optimized extraction condition was characterized in order to have a better idea about its chemical composition. This extract was found to contain flavonoids, proteins, and minerals in the following concentrations: $1.68 \pm 0.06 \mathrm{mg}$ QE/g CS, $8.73 \pm 0.73 \mathrm{mg} / \mathrm{g} \mathrm{CS}$, and $0.50 \pm$ $0.10 \mathrm{mg} / \mathrm{ml} \mathrm{CS}$ extract, respectively.

After validating the optimum extraction conditions, a comparative analysis was carried out taking into account the content of phenolic compounds (PC) obtained from CS under the optimized conditions and other results reported in the literature for the recovery of these compounds from CS using different extraction methods. As can be seen in Table 4, the results obtained in the present study (12.81 mg GAE/g CS) were significantly higher than those obtained by Machado et al. (2011) by solid-state fermentation with Penicillium purpurogenum (3.47 mg GAE/g CS), and by Narita and Inouye (2012) during the extraction of CS with water at $80{ }^{\circ} \mathrm{C}$ (7.00 $\mathrm{mg} \mathrm{GAE} / \mathrm{g} \mathrm{CS}$ ), and were comparable to the results obtained by Murthy and Naidu (2012) using isopropanol $60 \%$ 
as extraction solvent (13.20 mg GAE/g CS). Although isopropanol has been used as extraction solvent to recover compounds from different natural sources, the toxic characteristic of this solvent arise serious issues when the purpose of the compounds extracted is the application in food and pharmaceutical industries. Ethanol, which was used in the present study, is much less toxic than isopropanol and was able to promote similar extraction results, being, therefore, more indicated for use in these kinds of applications.

\section{Conclusions}

Coffee silverskin was demonstrated to be an agroindustrial waste rich in antioxidant phenolic compounds, which can be recovered by a process of solid-liquid extraction. Ethanol was an efficient solvent to extract antioxidant phenolic compounds from this raw material, particularly when used at $60 \%(v / v)$ and in a ratio of $35 \mathrm{ml} / \mathrm{g}$ dry matter, during $30 \mathrm{~min}$ at $60-65^{\circ} \mathrm{C}$. These findings are of great relevance because antioxidant phenolic compounds have enormous functional properties and countless applications in several industrial areas, which made then possible the valorization of this waste material. Additionally, the obtainment of antioxidant phenolic compounds from coffee silverskin could have an advantageous impact in the final cost of the product since this coffee waste is a low cost feedstock.

Acknowledgments This work was supported by the Portuguese Foundation for Science and Technology (FCT). The authors gratefully acknowledge Teresa Conde, student of Biological Engineering, for the help and interest in this work.

\section{References}

Alothman, M., Bhat, R., \& Karim, A. A. (2009). Antioxidant capacity and phenolic content of selected tropical fruits from Malaysia, extracted with different solvents. Food Chemistry, 115(3), 785-788.

Ao, C., Higa, T., Khanh, T. D., Upadhyay, A., \& Tawata, S. (2011). Antioxidant phenolic compounds from Smilax sebeana Miq. LWT- Food Science and Technology, 44(7), 1681-1686.

Benzie, I. F., \& Strain, J. J. (1996). The ferric reducing ability of plasma (FRAP) as a measure of "antioxidant power": The FRAP assay. Analytical Biochemistry, 239(1), 70-76.

Borrelli, R. C., Esposito, F., Napolitano, A., Ritieni, A., \& Fogliano, V. (2004). Characterization of a new potential functional ingredient: Coffee silverskin. Journal of Agricultural and Food Chemistry, 52(5), 1338-1343.

Bradford, M. M. (1976). A rapid and sensitive method for the quantification of microgram quantities of protein using the principles of protein-dye binding. Analytical Biochemistry, 72, 248-255.

Chang, C.-C., Yang, M.-H., Wen, H.-M., \& Chern, J.-C. (2002). Estimation of total flavonoid content in propolis by two complementary colorimetric methods. Journal of Food and Drug Analysis, 10(3), 178-182.
Chirinos, R., Rogez, H., Campos, D., Pedreschi, R., \& Larondelle, Y. (2007). Optimization of extraction conditions of antioxidant phenolic compounds from mashua (Tropaeolum tuberosum Ruíz \& Pavón) tubers. Separation and Purification Technology, 55(2), 217-225.

Cortazar, E., Bartolomé, L., Delgado, A., Etxebarria, N., Fernández, L. A., Usobiaga, A., \& Zuloaga, O. (2005). Optimisation of microwaveassisted extraction for the determination of nonylphenols and phthalate esters in sediment samples and comparison with pressurised solvent extraction. Analytica Chimica Acta, 534(2), 247-254.

Dorta, E., Lobo, M. G., \& González, M. (2012). Reutilization of mango by-products: Study of the effect of extraction solvent and temperature on their antioxidant properties. Journal of Food Science, 77, C80-C88.

Gan, C.-Y., \& Latiff, A. A. (2011). Optimisation of the solvent extraction of bioactive compounds from Parkia speciosa pod using response surface methodology. Food Chemistry, 124(3), 1277-1283.

Hidalgo, M., Sánchez-Moreno, C., \& de Pascual-Teresa, S. (2010). Flavonoid-flavonoid interaction and its effect on their antioxidant activity. Food Chemistry, 121(3), 691-696.

Jiménez, J. P., Serrano, J., Tabernero, M., Arranz, S., Díaz-Rubio, M. E., García-Diz, L., Goñi, I., \& Saura-Calixto, F. (2008). Effects of grape antioxidant dietary fiber in cardiovascular disease risk factors. Nutrition, 24(7-8), 646-653.

Karadag, A., Ozcelik, B., \& Saner, S. (2009). Review of methods to determine antioxidant capacities. Food Analytical Methods, 2(1), 41-60.

Kim, D.-O., \& Lee, C. Y. (2002). Extraction and isolation of polyphenolics. In R. E. Wrolstad (Ed.), Current protocols in food analytical chemistry (pp. I1.2.1-I1.2.12). New York: Wiley.

Lafka, T. I., Sinanoglou, V., \& Lazos, E. S. (2007). On the extraction and antioxidant activity of phenolic compounds from winery wastes. Food Chemistry, 104(3), 1206-1214.

Lebovka, N., Vorobiev, N., \& Chemat, E. (2011). Enhancing extraction processes in the food industry. Boca Raton: CRC Press.

Liu, F. F., Ang, C. Y. W., \& Springer, D. (2000). Optimization of extraction conditions for active components in Hypericum perforatum using response surface methodology. Journal of Agricultural and Food Chemistry, 48(8), 3364-3371.

Machado, E. M. S., Rodriguez-Jasso, R. M., Teixeira, J. A., \& Mussatto, S. I. (2011). Growth of fungal strains on coffee industry residues with removal of polyphenolic compounds. Biochemical Engineering, 60, 87-90.

Markom, M., Hasan, M., Daud, W. R. W., Singh, H., \& Jahim, J. M. (2007). Extraction of hydrolysable tannins from Phyllanthus niruri Linn.: Effects of solvents and extraction methods. Separation and Purification Technology, 52(3), 487-496.

Martins, S., Aguilar, C. N., Garza-Rodriguez, I., Mussatto, S. I., \& Teixeira, J. A. (2010). Kinetic study of nordihydroguaiaretic acid recovery from Larrea tridentata by microwave-assisted extraction. Journal of Chemical Technology and Biotechnology, 85(8), $1142-1147$.

Martins, S., Mussatto, S. I., Martínez-Avila, G., Montañez-Saenz, J., Aguilar, C. N., \& Teixeira, J. A. (2011). Bioactive phenolic compounds: Production and extraction by solid-state fermentation. A review. Biotechnology Advances, 29, 365-373.

Meneses, N. G. T., Martins, S., Teixeira, J. A., \& Mussatto, S. I. (2013). Influence of extraction solvents on the recovery of antioxidant phenolic compounds from brewer's spent grains. Separation and Purification Technology, 108, 152-158.

Murthy, P. S., \& Naidu, M. M. (2012). Recovery of phenolic antioxidants and functional compounds from coffee industry byproducts. Food and Bioprocess Technology, 5(3), 897-903.

Mussatto, S. I., Machado, E. M. S., Martins, S., \& Teixeira, J. A. (2011a). Production, composition, and application of coffee and its industrial residues. Food and Bioprocess Technology, 4(5), 661-672. 
Mussatto, S. I., Ballesteros, L. F., Martins, S., \& Teixeira, J. A. (2011b). Extraction of antioxidant phenolic compounds from spent coffee grounds. Separation and Purification Technology, 83, 173-179.

Narita, Y., \& Inouye, K. (2012). High antioxidant activity of coffee silverskin extracts obtained by the treatment of coffee silverskin with subcritical water. Food Chemistry, 135(3), 943-949.

Pompeu, D. R., Silva, E. M., \& Rogez, H. (2009). Optimisation of the solvent extraction of phenolic antioxidants from fruits of Euterpe oleracea using response surface methodology. Bioresource Technology, 100(23), 6076-6082.

Prasad, K. N., Yang, E., Yi, C., Zhao, M., \& Jiang, Y. (2009). Effects of high pressure extraction on the extraction yield, total phenolic content and antioxidant activity of longan fruit pericarp. Innovative Food Science \& Emerging Technologies, 10(2), 155-159.

Prasad, K. N., Hassan, F. A., Yang, B., Kong, K. W., Ramanan, R. N., Azlan, A., \& Ismail, A. (2011). Response surface optimisation for the extraction of phenolic compounds and antioxidant capacities of underutilised Mangifera pajang Kosterm. peels. Food Chemistry, 128(4), 1121-1127.

Rodríguez-Meizoso, I., Jaime, L., Santoyo, S., Señoráns, F., Cifuentes, A., \& Ibáñez, E. (2010). Subcritical water extraction and characterization of bioactive compounds from Haematococcus pluvialis microalga. Journal of Pharmaceutical and Biomedical Analysis, 51(2), 456-463.
Singleton, V. L., \& Rossi, J. A. (1965). Colorimetry of total phenolics with phosphomolybdic-phosphotungstic acid reagents. American Journal of Enology and Viticulture, 16(3), 144-158.

Spigno, G., Tramelli, L., \& De Faveri, D. M. (2007). Effects of extraction time, temperature and solvent on concentration and antioxidant activity of grape marc phenolics. Journal of Food Engineering, 81(1), 200-208.

Stratil, P., Klejdus, B., \& Kubáň, V. (2007). Determination of phenolic compounds and their antioxidant activity in fruits and cereals. Talanta, 71(4), 1741-1751.

Trabelsi, N., Megdiche, W., Ksouri, R., Falleh, H., Oueslati, S., Soumaya, B., Hajlaoui, H., \& Abdelly, C. (2010). Solvent effects on phenolic contents and biological activities of the halophyte Limoniastrum monopetalum leaves. LWT- Food Science and Technology, 43(4), 632-639.

Wang, S. Y., \& Lin, H.-S. (2000). Antioxidant activity in fruits and leaves of blackberry, raspberry, and strawberry varies with cultivar and developmental stage. Journal of Agricultural and Food Chemistry, 48(2), 140-146.

Wijekoon, M. M. J. O., Bhat, R., \& Karim, A. A. (2011). Effect of extraction solvents on the phenolic compounds and antioxidant activities of bunga kantan (Etlingera elatior Jack.) inflorescence. Journal of Food Composition and Analysis, 24(4), 615-619. 